\title{
Myostatin and insulin-like growth factor-I and -II expression in the muscle of rats exposed to the microgravity environment of the NeuroLab space shuttle flight
}

\author{
R Lalani, S Bhasin, F Byhower, R Tarnuzzer ${ }^{1}$, M Grant $^{1}$, \\ R Shen, S Asa ${ }^{2}$, S Ezzat ${ }^{2}$ and N F Gonzalez-Cadavid \\ Division of Endocrinology, Metabolism, and Molecular Medicine, Charles R Drew University, Los Angeles, California, USA \\ ${ }^{1}$ Division of Endocrinology, University of Florida, Gainesville, Florida, USA \\ ${ }^{2}$ Division of Medicine, University of Toronto, Toronto, Canada \\ (Requests for offprints should be addressed to N F Gonzalez-Cadavid, Charles R Drew University of Medicine and Science, 1731 E 120 th Street, Los Angeles, \\ California 90059, USA; Email: ncadavid@ucla.edu)
}

\begin{abstract}
The mechanism of the loss of skeletal muscle mass that occurs during spaceflight is not well understood. Myostatin has been proposed as a negative modulator of muscle mass, and IGF-I and IGF-II are known positive regulators of muscle differentiation and growth. We investigated whether muscle loss associated with spaceflight is accompanied by increased levels of myostatin and a reduction in IGF-I and -II levels in the muscle, and whether these changes correlate with an increase in muscle proteolysis and apoptosis. Twelve male adult rats sent on the 17-day NASA STS-90 NeuroLab space flight were divided upon return to earth into two groups, and killed either 1 day later (R1) or after 13 days of acclimatization (R13). Ground-based control rats were maintained for the same periods in either vivarium (R3 and R15, respectively), or flight-simulated cages (R 5 and R17, respectively). RNA and protein were isolated from the tibialis anterior, biceps femoris, quadriceps, and gastrocnemius muscles. Myostatin, IGF-I, IGF-II and proteasome 2c mRNA concentrations were determined by reverse transcription/PCR; myostatin and ubiquitin mRNA were also measured by Northern blot analysis; myostatin protein was estimated by immunohistochemistry; the apoptotic index and the release of 3-methylhistidine were determined respectively by the TUNEL assay and by HPLC. Muscle weights were 19-24\% lower in the R1 rats compared with the control R3 and R5 rats, but were not significantly different after the recovery period. The myostatin $/ \beta$-actin mRNA ratios (means \pm S.E.M.) were higher in the muscles of the R1 rats compared with the
\end{abstract}

control R5 rats: $5 \cdot 0$-fold in tibialis $(5 \cdot 35 \pm 1 \cdot 85$ vs $1 \cdot 07 \pm 0 \cdot 26), 3 \cdot 0$-fold in biceps $(2 \cdot 46 \pm 0 \cdot 70$ vs $0 \cdot 81 \pm$ $0 \cdot 04), 1 \cdot 9$-fold in quadriceps $(7 \cdot 84 \pm 1 \cdot 73$ vs $4 \cdot 08 \pm 0 \cdot 52)$, and $2 \cdot 2$-fold in gastrocnemius $(0.99 \pm 0.35$ vs $0.44 \pm$ $0 \cdot 17)$. These values also normalized upon acclimatization. Our antibody against a myostatin peptide was validated by detection of the recombinant human myostatin protein on Western blots, which also showed that myostatin immunostaining was increased in muscle sections from R1 rats, compared with control R3 rats, and normalized upon acclimatization. In contrast, IGF-II mRNA concentrations in the muscles from R1 rats were $64-89 \%$ lower than those in R3 animals. With the exception of the gastrocnemius, IGF-II was also decreased in R5 animals maintained in flight-simulated cages, and normalized upon acclimatization. The intramuscular IGF-I mRNA levels were not significantly different between the spaceflight rats and the controls. No increase was found in the proteolysis markers 3-methyl histidine, ubiquitin mRNA, and proteasome 2C mRNA. In conclusion, the loss of skeletal muscle mass that occurs during spaceflight is associated with increased myostatin mRNA and protein levels in the skeletal muscle, and a decrease in IGF-II mRNA levels. These alterations are normalized upon restoration of normal gravity and caging conditions. These data suggest that reciprocal changes in the expression of myostatin and IGF-II may contribute to the multifactorial pathophysiology of muscle atrophy that occurs during spaceflight.

Journal of Endocrinology (2000) 167, 417-428

\section{Introduction}

Experimental animals and humans experience substantial loss of skeletal muscle mass and function during space flights (Baldwin 1996, Baldwin et al. 1996, Vernikos 1996, Booth \& Criswell 1997, Desplanches 1997); this has emerged as a significant impediment to NASA's plans for human voyages of space exploration. Analogous but not 
identical changes occur in the muscles during unloading produced by caudal suspension in animals or prolonged bed rest in humans (Ferrando et al. 1996, Bamman et al. 1998, Mozdziak et al. 1998, Wehling et al. 2000). Muscle organ cultures sent in spaceflight also demonstrate atrophy in response to microgravity (Vandenburgh et al. 1999).

The molecular mechanisms of sarcopenia that occurs during spaceflight are unknown. In both the spaceflight rats and the hindlimb-suspended rats, there is an early reduction in protein synthesis, accompanied by a less consistent increase in protein degradation reflected by a stimulation of the ubiquitin/proteasome pathway (Baldwin 1996, Mitch \& Goldberg 1996, Both \& Criswell 1997, Desplanches 1997, Stein \& Schluter 1997). The astronauts and experimental animals also experience systemic changes in their hormonal milieu during spaceflight, including decreased testosterone and growth hormone levels, and increased glucocorticoid levels (Amann et al. 1992, Merrill et al. 1992, Stein \& Schluter 1997, Strollo et al. 1998a,b). The fact that antigravity muscles are preferentially atrophied during space flights suggests that the balance of local muscle growth factors is as important in the pathophysiology of the observed sarcopenia as systemic hormonal changes.

The intramuscular concentrations of insulin-like growth factor-I (IGF-I), an important modulator of skeletal muscle growth (Husmann et al. 1996), have been reported to be decreased in response to hindlimb suspension, aging and glucocorticoid administration (Welle \& Thornton 1997, Adam 1998, Gayan-Ramirez et al. 1999, Suliman et al. 1999), but no information is available on the changes in muscle IGF-I levels during spaceflight. Another member of the IGF family, IGF-II, is involved in muscle differentiation and regeneration (Marsh et al. 1997, Yoshiko et al. 1998, Gayan-Ramirez et al. 1999, Kaliman et al. 1999, Keller et al. 1999), and has been implicated in the maintenance of skeletal muscle mass in pig breeds with exceptional muscularity and strength (Jeon et al. 1999, Nezer et al. 1999). However, we do not know if IGF-II expression in the muscle is affected by spaceflight. Myostatin, a member of the transforming growth factor (TGF)- $\beta$ family of growth factors, has been proposed as an inhibitor of skeletal muscle mass (McPherron et al. 1997, McPherron \& Lee 1997, Szabo et al. 1998). Inactivating mutations of the myostatin gene in cattle and mice are associated with generalized increase in skeletal muscle (Kambadur et al. 1997, McPherron \& Lee 1997, Grobet et al. 1998, Szabo et al. 1998). Similarly, mice that were made null for the myostatin gene product by homologous recombination have increased body weight (McPherron \& Lee 1997). Myostatin levels are increased in the serum of HIV-infected patients with wasting (Gonzalez-Cadavid et al. 1998), elderly men and women with sarcopenia (Yarashesky et al. 1999), and in the skeletal muscle in a rat model of aging (Mallidis et al. 1999) and during hindlimb unloading (Baldwin et al. 1996). These observations have led to the speculation that increased myostatin expression might contribute to the sarcopenia observed in association with aging, chronic illness and spaceflight.

We hypothesized that the loss of muscle mass in response to microgravity might be due to a perturbation of the homeostatic balance between anabolic and catabolic factors produced locally in the muscle. We postulated that exposure to microgravity might induce the negative modulators such as myostatin and downregulate positive modulators such as IGF-I and -II, thus tilting the homeostatic balance towards loss of muscle mass. We, therefore, measured the intramuscular concentrations of myostatin, and IGF-I and -II mRNAs in rats exposed to the microgravity environment of the NeuroLab space flight, and during recovery at $1 G$ after the animals had returned to earth (Highstein \& Cohen 1999). We have compared the changes in the expression of these genes with apoptotic index and markers of muscle protein breakdown.

\section{Materials and Methods}

\section{Experimental groups}

Twelve Fischer 344 rats were sent into space aboard the NASA STS-90 NeuroLab space flight for 17 days (Highstein \& Cohen 1999) and, upon return to earth, were divided into two groups of six animals each. The animals in one group, referred to as 'microgravity, nonacclimated' (R1), were killed 1 day after landing, and those in the other group, referred to as 'microgravity, acclimated', were killed 13 days after landing (R13). Weight-matched, ground-based control rats were maintained on earth, either in regular vivarium cages with a $48 \mathrm{~h}$ asynchronous delay $(n=12)$, or in flight cages similar to those used in the space flight with a $96 \mathrm{~h}$ asynchronous delay $(n=12)$. The asynchronous delay is the period elapsed from the launch of the mission till the time when the control animals were entered in the experimental protocol. In this way both the microgravity-exposed animals and their ground-based controls were matched for the time spent in the respective type of housing. One-half of the vivarium control rats were killed on day 3 after shuttle landing, and are referred to as 'vivarium, nonacclimated' (R3), and the remainder on day 15 after landing, and referred to as 'vivarium, acclimated' (R15). The control rats in cages similar to those used in the shuttle flight were killed either on day 5 after landing, and were referred to as 'simulation, non-acclimated' (R5), or on day 17 after landing and transfer to normal cages, named 'simulation, acclimated' (R17).

Rats were exposed to reversed $12 \mathrm{~h}: 12 \mathrm{~h}$ light-dark cycles for 53 days before killing. All dissections were performed during the first half of the rat's dark cycle. Animals were weighed and killed at scheduled times under anesthesia, and the following skeletal muscles from the hindlegs were dissected out: tibialis anterior, biceps 
femoris, quadriceps and gastrocnemius. Muscles isolated from one hindlimb were snap-frozen in liquid nitrogen and stored at $-80{ }^{\circ} \mathrm{C}$. Muscle tissue from the other hindlimb was cut into several pieces, dropped into $10 \%$ formalin, fixed for $24 \mathrm{~h}$, washed in PBS, and maintained in PBS at $4{ }^{\circ} \mathrm{C}$ for subsequent immunohistochemistry.

\section{Estimation of myostatin $m R N A$}

Total RNA was extracted from about $100 \mathrm{mg}$ muscle tissue by applying Trizol reagent. The quality of the RNA preparation was checked by agarose gel electrophoresis and ethidium bromide staining. Aliquots containing $0 \cdot 1$ and $0.5 \mu \mathrm{g}$ RNA were submitted to reverse transcription (RT) with a 16-mer oligo-dT primer, as previously described (Gonzalez-Cadavid et al. 1998). The subsequent PCR reaction was carried out with $1 / 10$ of the $\mathrm{RT}$ reaction in a total volume of $25 \mu \mathrm{l}$. Sense and antisense 20-mer primers $(0.2 \mu \mathrm{M})$ were added for rat myostatin (McPherron et al. 1997) (nucleotides (nts) 61 and 465, respectively, in Genebank accession number AF019624), or reference genes, $\beta$-actin (nts 1552 and 2991, in Genebank accession number J00691), or 3-glyceraldehyde phosphate dehydrogenase (GADPH, nts 4219 and 4372, Ercolani et al. 1988). The thermal amplification of the $404 \mathrm{bp}$ myostatin DNA fragments was conducted after a 3 min step of denaturation at $94^{\circ} \mathrm{C}$, by 35 cycles at $94{ }^{\circ} \mathrm{C}$ $(35 \mathrm{~s}), 58^{\circ} \mathrm{C}(45 \mathrm{~s})$, and $72{ }^{\circ} \mathrm{C}(80 \mathrm{~s})$, and a final step at $72{ }^{\circ} \mathrm{C}$ for $7 \mathrm{~min}$. The $153 \mathrm{bp}$ GADPH and $793 \mathrm{bp} \beta$-actin bands were obtained by 19 PCR cycles under the same conditions. Preliminary experiments conducted at several dilutions and times indicated that these were the optimum conditions to keep amplifications of the selected myostatin, $\beta$-actin, and GADPH DNA sequences within the linear range. Myostatin and reference gene PCR amplifications for each muscle were performed simultaneously for each individual animal. The relative intensity of the bands stained by ethidium bromide after agarose gel electrophoresis was measured by densitometry with ScanAnalysis, and values were expressed as myostatin/reference gene ratios.

In certain cases, $20 \mu \mathrm{g}$ of total RNA were submitted to Northern blot hybridization using a 1277 bp cDNA probe obtained by PCR amplification from the cloned human myostatin cDNA (Gonzalez-Cadavid et al. 1998). The human probe has a $95 \%$ homology to the corresponding rat myostatin region. The filters were stripped and submitted to new hybridization with a $1233 \mathrm{bp}$ cDNA probe for rat GADPH obtained by restriction enzyme digestion from the cloned fragment.

\section{Estimation of IGF-I and -II $m R N A$}

IGF-I and -II mRNA levels were measured by RT-PCR. Initially, IGF-I and -II cDNAs were obtained from $0 \cdot 2 \mu \mathrm{g}$ total RNA using oligo(dT)-primed reverse transcription;
$1 / 20$ th of the RT reaction was submitted to PCR in the presence of five serial 10-fold dilutions starting at $8.5 \times 10^{8}$ copies per reaction of competitive synthetic multiplex templates (Tarnuzzer et al. 1996, Pfaffl et al. 1998). Sequences for the IGF-I antisense and sense primers were respectively: 5'-GTAGGTCTTGTTTCC TGCAC-3', and 5'-CACATCTCTTCTACCTGGC-3'. Sequences for the IGF-II antisense and sense primers were respectively: 5'-TCTCTGAACGCTTCGAGCTC-3', and 5'-GAGGCTGCTTCCCGCAGCTG-3'. Amplification reactions were carried out over 40 cycles at $94{ }^{\circ} \mathrm{C}$ $(1.5 \mathrm{~min}), 58^{\circ} \mathrm{C}(2 \mathrm{~min})$, and $72{ }^{\circ} \mathrm{C}(3 \mathrm{~min})$. The IGF-I and -II product sizes were 376 and $247 \mathrm{bp}$, respectively, whereas the template product size was $517 \mathrm{bp}$. The fragments were separated on agarose gel electrophoresis and the band images were scanned using Scion Image software. The $\log$ of the ratio of band intensities within each lane was plotted against the log of the template copy number and the target mRNA copy number was determined in a region where the ratio of template and target band intensities was equal to one.

\section{Validation of myostatin antibody and immunohistochemistry}

A cDNA construct encoding the sequence corresponding to the putative myostatin 111 amino acid protein (McPherron et al. 1997) was prepared with an artificial start codon ATG immediately before the Arg-Arg-AspPhe amino acid sequence containing the precursor cleavage site, and a pentahistidine tag at the $3^{\prime}$ end (Taylor et al. 2000). This plasmid was named pDES-Mst111(H). Drosophila DES cells were transfected with these vectors and induced with $\mathrm{Cu}^{2+}$ (Kirkpatrick \& Shatzman 1999), and cell protein was prepared as a side-product from RNA isolation with the Trizol RNA procedure. A similar protein expressed in E. coli, but carrying six histidines preceded by a six amino acid stretch at the amino terminus of the fusion protein instead of the carboxy-end tag was kindly provided by Dr Fred Kull of Glaxo-Wellcome Laboratories. This plasmid was named pEC-Mst111(H).

For antibody validation, aliquots of the protein extracted from the induced and non-induced transfected DES cells or the purified recombinant myostatin protein were heated at $95^{\circ} \mathrm{C}$ for $5 \mathrm{~min}$ in a denaturing-reducing buffer containing $1 \%$ SDS and $1.25 \%$ mercaptoethanol, and analyzed on $12 \%$ polyacrylamide gels. The proteins were detected in a two-step immunodetection assay, using rabbit polyclonal antibody B against human myostatin (Gonzalez-Cadavid et al. 1998) at a 1:1000 dilution and immunoperoxidase-linked anti-rabbit IgG (1:2000). Bands were visualized in a luminol-based reaction on $\mathrm{X}$-ray film. Other aliquots from the cell protein extract were submitted to Western blot transfer and detected by using either a primary mouse monoclonal antibody against the polyhistidine carboxy-end tag, or a single-step immunodetection with the primary antibody linked to 
immunoperoxidase. For the detection of endogenous myostatin in muscle, approximately $30-50 \mathrm{mg}$ of muscle tissue was homogenized in a buffer containing protease inhibitors (Gonzalez-Cadavid et al. 1998). SDS was added to $1 \%$, and aliquots containing $20 \mathrm{mg}$ protein were submitted to Western blots, using only anti-myostatin antibody B. In certain cases, to verify specificity, non-immune rabbit IgG was applied to sections of the membrane blots instead of the primary anti-peptide antibody, or the primary antibody was omitted.

For immunohistochemical detection of myostatin, the formalin-fixed, paraffin-embedded skeletal muscle sections (Gonzalez-Cadavid et al. 1998) were deparaffinized and the peroxidase activity was blocked. Sections were incubated with primary anti-myostatin antibody $(1: 500)$ overnight, and then with biotinylated linking reagent (Signet; 1:3) for $45 \mathrm{~min}$, followed by diaminobenzidine for $5 \mathrm{~min}$. Sections were counterstained with hematoxylin and the staining intensity was graded visually from 0 to $4+$ in four adjacent sections per tissue specimen.

\section{Proteolysis and apoptosis markers}

The free 3-methylhistidine content in muscle was measured by HPLC amino acid analysis in supernates obtained by centrifugation of muscle homogenates in 20-60\% perchloric acid (Tayek 1996) at $15000 \mathrm{~g}$ for $10 \mathrm{~min}$. Ubiquitin mRNA was determined by hybridization of the Northern blots with a maize ubiquitin cDNA probe (Kho et al. 1997) that has $90 \%$ homology to the rat ubiquitin homologous region (Genebank accession number U54632). Proteasome subunit 2c mRNA was determined by RT-PCR applying 20-mer primers spanning nt 241-499 in the rat sequence (Genebank accession number M29859), using the procedure described for myostatin. Densitometric values were expressed as ratios to GAPDH.

The apoptotic index (Sinha-Hikim \& Swerdloff 1995) was determined by the TUNEL method, based on the ability of terminal deoxynucleotidyl transferase to catalyze template-independent addition of digoxenin-dUTP and dATP to $3^{\prime} \mathrm{OH}$ ends of DNA, generated by internucleosomal cleavage. The resulting heteropolymer was recognized with an antidigoxenin antibody conjugated to peroxidase. Deparaffinized sections $(5 \mu \mathrm{m})$ were treated with proteinase $\mathrm{K}$ and then with $\mathrm{H}_{2} \mathrm{O}_{2}$ to quench endogenous peroxidase, followed by the primary and secondary antisera and DAB staining. Counterstaining was done with $0.5 \%$ Methyl Green. The apoptotic index was calculated by dividing the number of apoptotic cells by the number of nuclei in the microscope field.

\section{Statistical analysis}

The data are expressed as means \pm s.E.M. The WilkShapiro test was used to establish whether the data were normally distributed. The outcome measures in the three groups were compared by one-way analysis of variance (ANOVA). If overall ANOVA revealed significant effect, further comparisons between groups were performed by using Tukey's post hoc test. The difference among groups was considered significant at $P<0 \cdot 05$.

\section{Results}

Effect of spaceflight on body weight and skeletal muscle mass

The body weights of rats that were sent into space and the two groups of ground-based controls were not significantly different prior to flight (mean \pm S.E.M.: $355 \pm 8 \mathrm{~g}$ for vivarium controls, $365 \pm 7 \mathrm{~g}$ for simulated controls and $367 \pm 10 \mathrm{~g}$ for microgravity-exposed rats). Immediately after returning to earth, the spaceflight rats weighed on average $5 \%$ less $(354 \pm 9 \mathrm{~g})$ than the vivarium $(374 \pm 7 \mathrm{~g})$ and simulation control $(377 \pm 4 \mathrm{~g})$ animals. After 13 days acclimatization on the ground, spaceflight rats still weighed significantly less $(349 \pm 7 \mathrm{~g})$ than the two groups of control animals (372 \pm 4 and $372 \pm 9 \mathrm{~g}$, respectively).

Exposure to microgravity during spaceflight caused a significant loss of mass in all muscle groups that we studied; the percentage decrease in muscle mass exceeded the decrease in body weight (Table 1). When compared with the simulated controls, the gastrocnemius, tibialis anterior, quadriceps and biceps femoris of the spaceflight rats had significantly less mass $(23 \cdot 8,20 \cdot 0,16 \cdot 5$ and $22 \cdot 9 \%$ reduction, respectively). After 13 days of acclimatization under ground-based conditions, the weights of the four skeletal muscle groups from the spaceflight rats were not significantly different from those of the control rats, with the exception of the gastrocnemius that weighed $18.4 \%$ less than the corresponding muscle group in the simulated controls.

\section{Intramuscular myostatin $m R N A$ concentrations}

The myostatin mRNA concentrations, measured by RTPCR, were normalized by dividing the intensity of the amplified 393 bp myostatin DNA band by the intensity of the $764 \mathrm{bp} \beta$-actin band. The identity of the myostatin band was confirmed by DNA sequencing of the amplified product from one of the gels. The nucleotide sequence of the amplified DNA product of the RT-PCR reaction had $100 \%$ homology to the rat myostatin DNA sequence. Mean myostatin mRNA concentrations (Table 2) were significantly higher in the gastrocnemius, tibialis anterior, quadriceps, and the biceps femoris muscle groups from the spaceflight rats than those in the simulated controls $(2 \cdot 3$, $5 \cdot 0,1 \cdot 9$ and $3 \cdot 0$-fold higher, respectively). After 13 days of acclimatization, myostatin mRNA concentrations were normalized in three muscle groups of the spaceflight rats to values not significantly different from those in the 
Table 1 Effect of microgravity on skeletal muscle mass

\begin{tabular}{|c|c|c|c|c|c|}
\hline & & Weight (g) & & & Percentage \\
\hline & Series & $\mathrm{CV}$ & CS & MG & MG/CS \\
\hline Muscle & & & & & \\
\hline Gastrocnemius & NA & $2 \cdot 02 \pm 0 \cdot 08^{a}$ & $2 \cdot 14 \pm 0 \cdot 05^{\mathrm{a}}$ & $1.63 \pm 0.09^{b}$ & $-23 \cdot 8$ \\
\hline & A & $2 \cdot 40 \pm 0 \cdot 10^{\mathrm{a}}$ & $2 \cdot 44 \pm 0 \cdot 17^{a}$ & $1.99 \pm 0 \cdot 16^{b}$ & $-18 \cdot 4$ \\
\hline Tibialis anterior & NA & $0 \cdot 66 \pm 0 \cdot 04^{a}$ & $0.65 \pm 0.02^{a}$ & $0.52 \pm 0.01^{b}$ & $-20 \cdot 0$ \\
\hline & A & $0.72 \pm 0.03$ & $0.69 \pm 0.04^{a}$ & $0.66 \pm 0.02$ & $-4 \cdot 3$ \\
\hline Quadriceps & NA & $3 \cdot 90 \pm 0 \cdot 12^{\mathrm{a}}$ & $3 \cdot 76 \pm 0 \cdot 32^{\mathrm{a}}$ & $3 \cdot 14 \pm 0 \cdot 19^{b}$ & $-16 \cdot 5$ \\
\hline & A & $3 \cdot 84 \pm 0 \cdot 20$ & $3.98 \pm 0.50$ & $4 \cdot 10 \pm 0 \cdot 20$ & $+3 \cdot 0$ \\
\hline Biceps femoris & NA & $2 \cdot 88 \pm 0 \cdot 25^{a}$ & $2 \cdot 84 \pm 0 \cdot 26^{a}$ & $2 \cdot 19 \pm 0 \cdot 27^{b}$ & $-22 \cdot 9$ \\
\hline & A & $3 \cdot 84 \pm 0 \cdot 13$ & $3 \cdot 55 \pm 0 \cdot 24$ & $3 \cdot 21 \pm 0 \cdot 20$ & -9.6 \\
\hline
\end{tabular}

Data are means \pm S.E.M. Significantly different values $(P<0 \cdot 05)$ in paired comparisons between two groups within either the non-acclimated (NA) or acclimated (A) series are denoted by different letters (a vs b). CV, vivarium control rats; CS, simulated control rats; MG, microgravity-exposed rats.

Table 2 Effect of microgravity on myostatin mRNA concentrations in the muscle estimated by RT-PCR. The amplified cDNA fragments were separated by agarose gel electrophoresis and the intensities of the myostatin bands were corrected by the intensities of the respective $\beta$-actin bands

\begin{tabular}{|c|c|c|c|c|c|}
\hline & \multirow[b]{2}{*}{ Series } & \multicolumn{3}{|c|}{ Mst/ $\beta$-actin ratios } & \multirow{2}{*}{$\begin{array}{l}\text { Ratio: } \\
\text { MG/CS }\end{array}$} \\
\hline & & $\mathrm{CV}$ & CS & MG & \\
\hline \multicolumn{6}{|l|}{ Muscle } \\
\hline \multirow[t]{2}{*}{ Gastrocnemius } & NA & $0 \cdot 58 \pm 0 \cdot 07^{a}$ & $0 \cdot 44 \pm 0 \cdot 17^{a}$ & $0.99 \pm 0.35^{b}$ & $2 \cdot 3$ \\
\hline & A & $0 \cdot 80 \pm 0 \cdot 16^{a}$ & $1 \cdot 39 \pm 0 \cdot 17^{\mathrm{b}}$ & $0 \cdot 66 \pm 0 \cdot 12^{a}$ & $0 \cdot 5$ \\
\hline \multirow[t]{2}{*}{ Tibialis anterior } & NA & $1 \cdot 35 \pm 0 \cdot 20^{\mathrm{a}}$ & $1 \cdot 07 \pm 0 \cdot 26^{\mathrm{a}}$ & $5 \cdot 35 \pm 1 \cdot 85^{b}$ & $5 \cdot 0$ \\
\hline & A & $0 \cdot 95 \pm 0 \cdot 18$ & $1 \cdot 09 \pm 0 \cdot 30$ & $1 \cdot 11 \pm 0 \cdot 09$ & $1 \cdot 0$ \\
\hline \multirow[t]{2}{*}{ Quadriceps } & NA & $6 \cdot 28 \pm 0 \cdot 40^{b}$ & $4 \cdot 08 \pm 0.52^{a}$ & $7 \cdot 84 \pm 1 \cdot 73^{b}$ & $1 \cdot 9$ \\
\hline & A & $5 \cdot 42 \pm 0 \cdot 54$ & $7 \cdot 30 \pm 2 \cdot 01$ & $8 \cdot 67 \pm 1.57$ & $1 \cdot 2$ \\
\hline \multirow[t]{2}{*}{ Biceps femoris } & NA & $0.85 \pm 0.04^{a}$ & $0.81 \pm 0.04^{\mathrm{a}}$ & $2 \cdot 46 \pm 0 \cdot 70^{b}$ & $3 \cdot 0$ \\
\hline & A & $0 \cdot 65 \pm 0 \cdot 10$ & $0 \cdot 45 \pm 0 \cdot 04$ & $0 \cdot 52 \pm 0 \cdot 07$ & $1 \cdot 1$ \\
\hline
\end{tabular}

Data are means \pm S.E.M. Significantly different values $(P<0.05)$ in paired comparisons between two groups within either the non-acclimated or acclimated series are denoted by different letters (a vs b).

simulated controls; the exception was the gastrocnemius, in which myostatin mRNA concentrations in the microgravity-exposed rats were lower.

The myostatin mRNA concentrations in the tibialis anterior were also determined by Northern blot analysis (Fig. 1, left) and, when expressed as the ratio of the intensities of the myostatin and the GAPDH band, were on average $1 \cdot 7$-fold higher in spaceflight rats compared with vivarium controls.

Myostatin-immunoreactive protein concentrations in the skeletal muscle assessed by immunohistochemical staining

The myostatin-immunoreactive protein concentrations in the muscle cross-sections were measured by a semiquantitative immunohistochemical procedure. As a first step, it was essential to extend the initial characterization of the specificity of the anti-myostatin antibody B (Gonzalez-Cadavid et al. 1998) in terms of its ability to detect recombinant human myostatin proteins. A myo- statin cDNA construct that encodes the 111 amino acid carboxy-terminal protein claimed to be the mature myostatin (McPherron et al. 1997) was prepared in a Drosophila expression vector. Upon transfection into the homologous DES cells, this vector allows for a more faithful processing of recombinant animal proteins than bacterial systems, without some of the disadvantages of the baculovirus system (Taylor et al. 2000). The product from this cDNA construct is a fusion protein that carries a penta-histidine tag at its carboxy-terminus. Induced DES cells had the expected $1.2 \mathrm{~kb}$ myostatin mRNA transcribed from this construct (data not shown). The homologous 111 amino acid protein, expressed in E. coli and carrying the penta-histidine tag at its amino-terminus, was also tested.

In Western blots performed under denaturing and reducing conditions, our antibody $\mathrm{B}$ detected the 111 amino acid myostatin protein made in E. coli (Fig. 2, top); increasing amounts of this recombinant protein resulted in a proportionate increase in the intensity of a $17 \mathrm{kDa}$ band, 


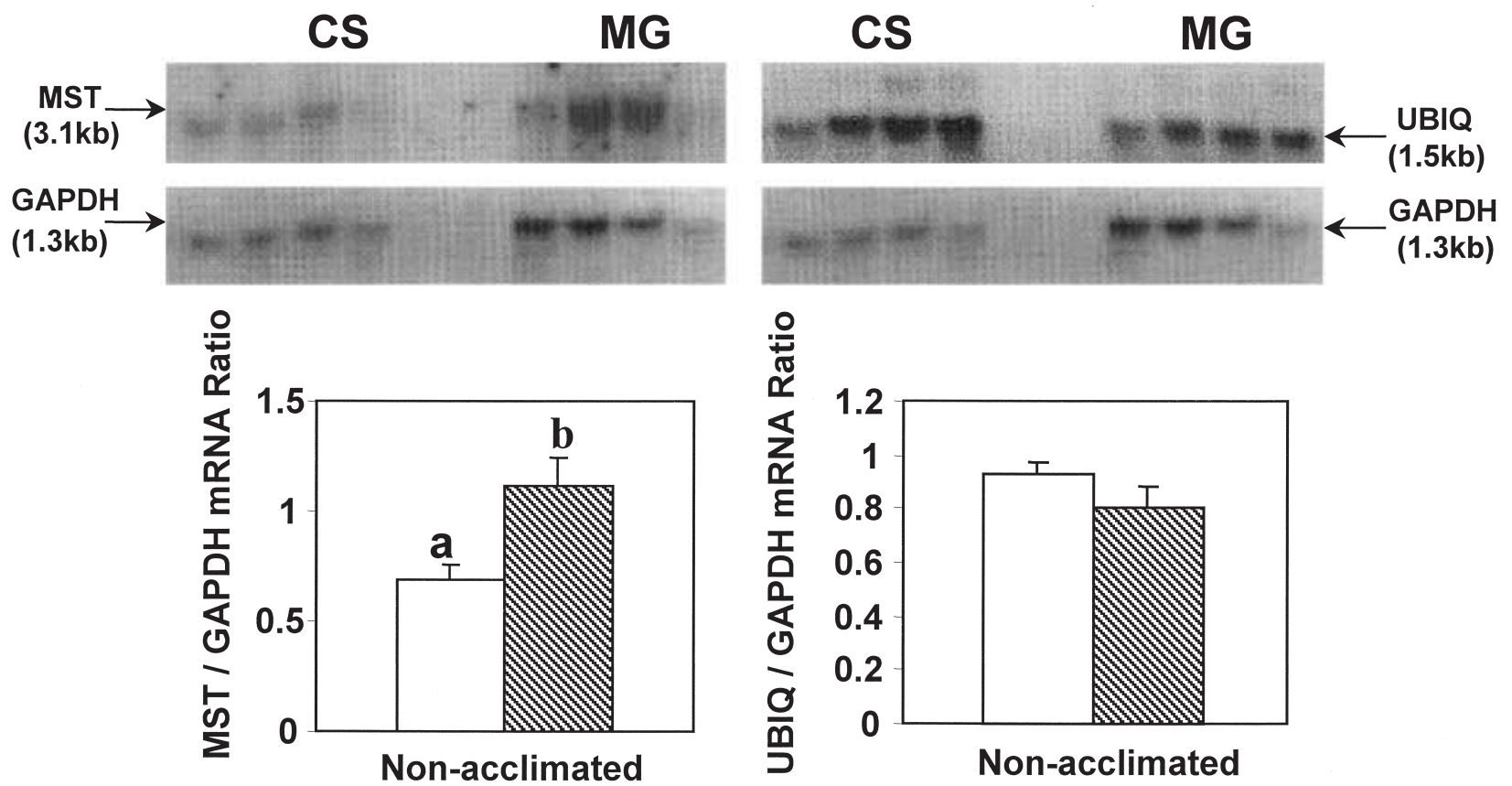

Figure 1 Effect of microgravity on myostatin (MST) and ubiquitin (UBIQ) mRNA levels in the tibialis anterior muscle measured by Northern blot analysis. RNA $(20 \mu \mathrm{g})$ was run on $1 \cdot 2 \%$ denaturing PAGE gels and subjected to Northern blot hybridization with ${ }^{32}$ P-labeled cDNA probes for myostatin and glyceraldehyde phosphate dehydrogenase (GAPDH), followed by autoradiography (top panel, left). The Northern blot was stripped and rehybridized with a probe for ubiquitin (top panel, right). The respective densitometric values are shown in the bottom panel. Data are means \pm S.E.M. a,b, $P<0 \cdot 05$. MG, microgravity-exposed rats; SC, control rats in flight simulated cages.

which appears by its size to correspond to the monomer with the polyhistidine tag. This $17 \mathrm{kDa}$ band is completely absent in the skeletal muscle preparations, which show only the 28-30 kDa band (Fig. 2, bottom). Surprisingly, a $28 \mathrm{kDa}$ band is also visible in the pure recombinant protein lanes (Fig. 2, top), overlapping the endogenous $28-30 \mathrm{kDa}$ band when the recombinant protein is added to the muscle extracts (Fig. 2, bottom). This endogenous band, together with a $49 \mathrm{kDa}$ band, presumably corresponding to the monomeric myostatin precursor, was detected in rat skeletal muscle homogenates, but no traces of the $14-17 \mathrm{kDa}$ bands seen with the recombinant myostatin were found in these preparations (Fig. 2, bottom right). The $28 \mathrm{kDa}$ band detected by the antibody in skeletal muscle preparations could not be dissociated in $6 \mathrm{M}$ urea (not shown). This suggests the formation of a recombinant myostatin dimer that does not fully dissociate inspite of the denaturing and reducing conditions employed in the Western blot, and that is slightly smaller than the $28-30 \mathrm{kDa}$ band observed in skeletal muscle extracts, as should be the case if the endogenous protein is glycosylated (Gonzalez-Cadavid et al. 1998).

The electrophoretic behavior of the recombinant myostatin protein is not an artifact of the E. coli preparation, as shown by the detection with antibody B of identical bands in the extracts from Drosophila cells transfected with the
cDNA encoding the 111 amino acid myostatin protein with a carboxy-terminus histidine tag. The $28 \mathrm{kDa}$ band is visible in induced cells and absent in the uninduced cells (Fig. 2, middle right). This $28 \mathrm{kDa}$ band is also detected with the anti-His antibody (middle left), establishing that the $28 \mathrm{kDa}$ band is related to the product of the cDNA encoding the 111 amino acid myostatin carboxy-terminal protein, and may originate either by its spontaneous dimerization or its association with other protein(s).

These data validated our antibody B that was then applied to tissue sections from the tibialis anterior from the spaceflight rats (Fig. 3, top left), showing that the immunoreactivity was more intense than in the same muscle of a simulation control rat (Fig. 3, top right). The immunostaining became undetectable in the muscle from another spaceflight rat that was acclimated on the ground for 13 days (Fig. 3, bottom left); and was even lower than that in an acclimated simulation control rat (Fig. 3, bottom right). A semi-quantitative assessment based on visual inspection of three to four adjacent sections per muscle specimen with multiple observations to cover the entire field, and grading from 0 to $4+$, demonstrated a significant increase in myostatin immunoreactivity in four nonacclimated microgravity-exposed animals compared with the corresponding four simulated controls $(2 \cdot 5 \pm 0 \cdot 3$ vs 


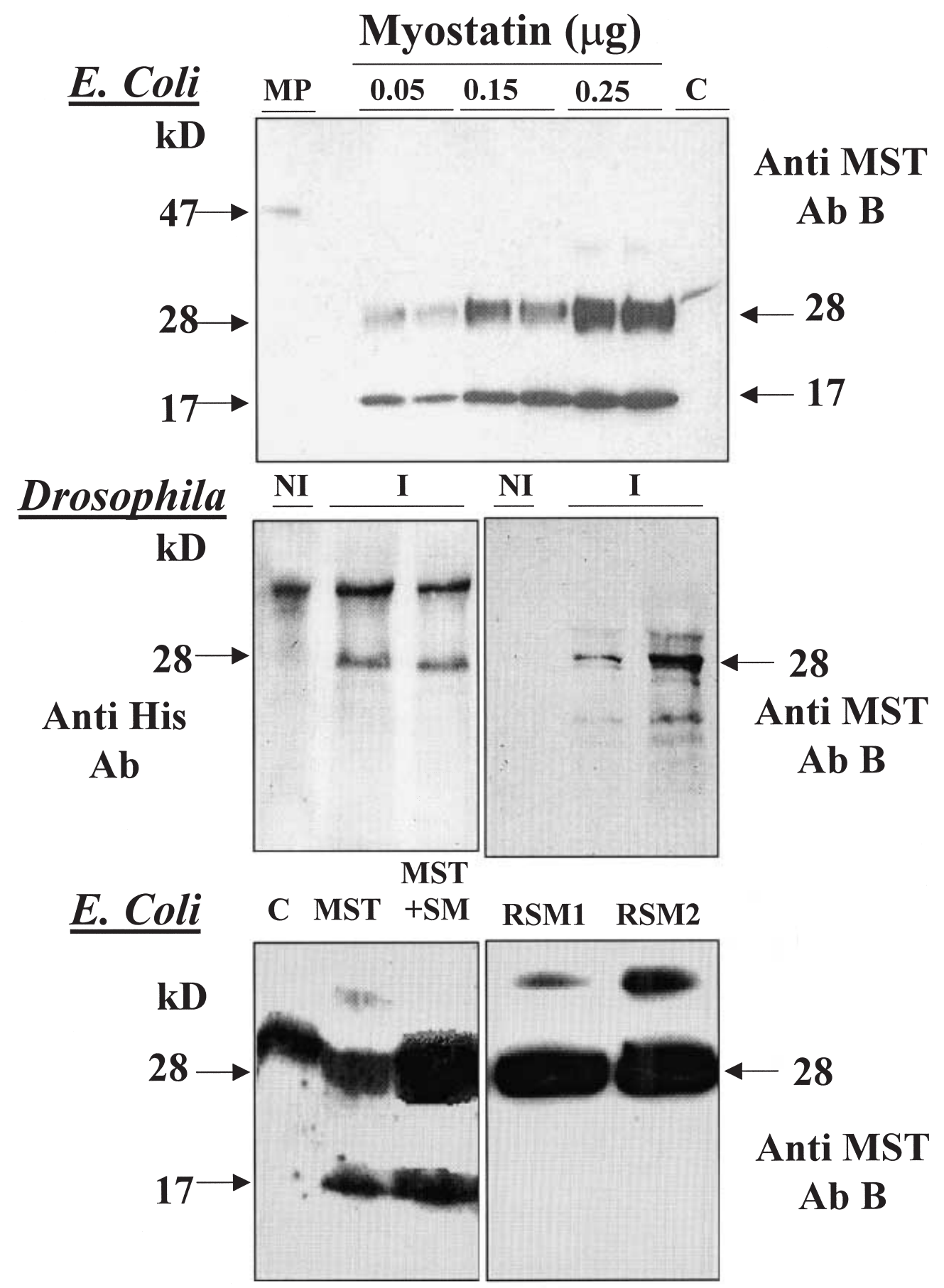

Figure 2 Validation of antibody B against a recombinant 111 amino acid, myostatin carboxy-terminal protein. Top panel: increasing amounts of a purified 111 amino acid myostatin carboxy-terminal protein made in E. coli, and carrying an amino-terminus-linked polyhistidine tag, were electrophoresed on $12.5 \%$ polyacrylamide gels. Western blots were performed with antibody B. MP, recombinant 375 amino acid myostatin protein produced in DES cells. C: control mouse skeletal muscle extract. Middle panel, a 111 amino acid myostatin protein containing a carboxy-terminus-linked polyhistidine tag was expressed in DES cells. Proteins were submitted to the same treatments, except that in addition to the Western blot with antibody B (right), incubation with polyHis antibody was applied (left). NI, non-induced; I, induced. Bottom panels, the 111 amino acid, myostatin protein was subjected to electrophoresis by itself (MST) or added to a mouse skeletal muscle preparation $(\mathrm{MST}+\mathrm{SM})$ before electrophoresis. C, control skeletal muscle extract alone. In another gel, two homogenates from rat tibialis anterior (RSM 1 and 2) were run separately. 

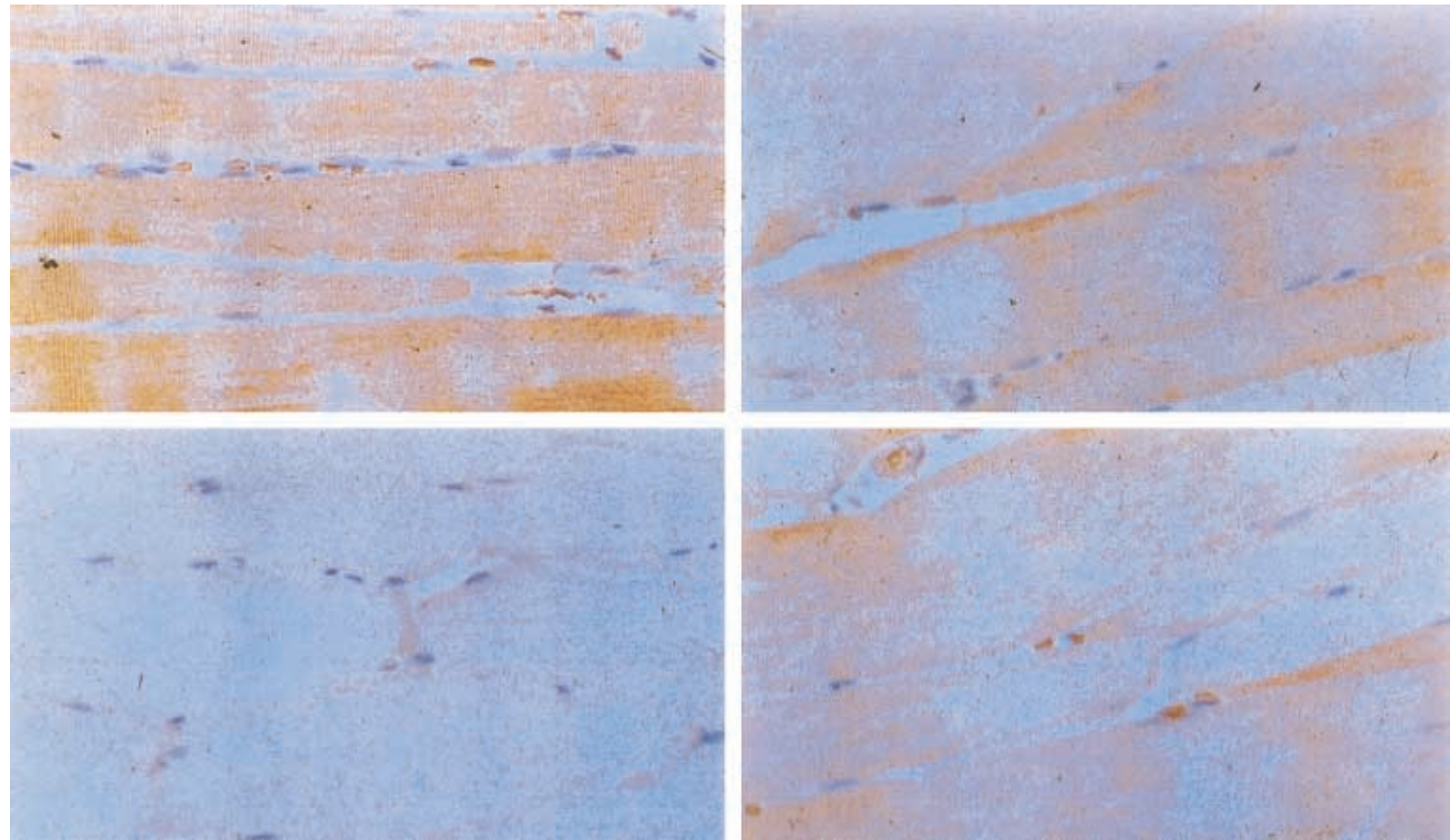

Figure 3 Immunohistochemical estimation of myostatin in skeletal muscle sections from rat exposed to microgravity. Representative sections of the tibialis anterior are shown on the top and bottom panels. Top left: microgravity-exposed animals, non-acclimated; top right: simulated control animal, non-acclimated; lower left: microgravity-exposed animal, acclimated; lower right: simulated control animal, acclimated.

$1 \cdot 25 \pm 0 \cdot 3)$. The same trend was observed in the gastrocnemius, but it was not significant. The staining intensity in the muscles from the rats exposed to microgravity was significantly reduced upon acclimatization in comparison with the simulated controls $(0.75 \pm 0.2$ vs $1.75 \pm 0.2$ in both cases). The other two muscles were not studied.

\section{Muscle IGF-I and -II $m R N A$ concentrations}

The IGF-I and -II mRNA concentrations were measured by a RT-PCR procedure (Ercolani et al. 1988) based on competition with an internal template, which yields an absolute IGF mRNA copy number per $\mu \mathrm{g}$ of total RNA. IGF-I mRNA concentrations in tibialis anterior were not significantly different between the spaceflight and vivarium control rats $\left(24 \cdot 8 \pm 12 \times 10^{11}\right.$ vs $29 \cdot 7 \pm 8 \times 10^{11}$ copies), but were lower in the simulated cage control animals $\left(16 \cdot 2 \pm 9 \times 10^{11}\right)$ when compared with the control vivarium animals.

The IGF-II mRNA concentrations (Table 3) were significantly lower in the gastrocnemius, tibialis anterior, quadriceps and biceps femoris of the non-acclimated spaceflight rats than those in the vivarium controls (mean decrease 64-89\%), but upon acclimatization were restored to normal values. In order to minimize differences due to interassay variability, all values are expressed in comparison with an intrassay control: the non-acclimated vivarium control rats. The IGF-II mRNA concentrations in the control vivarium animals varied according to muscle type, in the following order: tibialis anterior $>$ biceps femoris $>$ quadriceps $>$ gastrocnemius. The IGF-II mRNA concentrations in the muscles of rats in simulated cages were also significantly lower than those in vivarium controls in all muscle groups except for the gastrocnemius. There were no significant differences in IGF-II mRNA concentrations between the three groups after 13 days of acclimatization on the ground.

\section{Markers of protein breakdown}

To determine whether the microgravity-associated loss of muscle mass is due to increased proteolysis through the ubiquitin-proteasome pathway, we measured the ubiquitin mRNA concentrations by Northern blot analysis and proteasome $2 \mathrm{C}$ mRNA by quantitative RT-PCR. The relative concentrations of the 2.6 and $1.2 \mathrm{~kb}$ ubiquitin mRNA transcripts (Fig. 1, right) were not significantly different between the non-acclimated spaceflight rats and ground-based vivarium controls. The proteasome 2C mRNA concentrations normalized by using GADPH as the reference gene, also did not differ between the flight rats and the vivarium controls (data not shown). 
Table 3 Effect of microgravity on IGF-II mRNA levels in the muscle estimated by a competitive RT-PCR procedure

\begin{tabular}{|c|c|c|c|c|c|}
\hline & Series & CV & CS & MG & $\begin{array}{l}\text { Ratio: } \\
\text { MG/CV }\end{array}$ \\
\hline \multicolumn{6}{|l|}{ Muscle } \\
\hline \multirow[t]{2}{*}{ Gastrocnemius } & NA & $1 \cdot 00 \pm 0 \cdot 20^{\mathrm{a}}$ & $1 \cdot 55 \pm 0 \cdot 03^{\mathrm{a}}$ & $0 \cdot 11 \pm 0.03^{b}$ & $0 \cdot 11^{*}$ \\
\hline & A & $1 \cdot 17 \pm 0 \cdot 21$ & $0 \cdot 98 \pm 0 \cdot 22$ & $1 \cdot 58 \pm 0 \cdot 19$ & $1 \cdot 35$ \\
\hline \multirow[t]{2}{*}{ Tibialis anterior } & NA & $1.00 \pm 0.05^{\mathrm{a}}$ & $0 \cdot 19 \pm 0 \cdot 17^{b}$ & $0 \cdot 17 \pm 0 \cdot 04^{b}$ & $0 \cdot 17^{*}$ \\
\hline & A & $1 \cdot 07 \pm 0 \cdot 10$ & $0.81 \pm 0.08$ & $0.90 \pm 0.07$ & $0 \cdot 85$ \\
\hline \multirow[t]{2}{*}{ Quadriceps } & NA & $1 \cdot 00 \pm 0 \cdot 26^{\mathrm{a}}$ & $0 \cdot 24 \pm 0 \cdot 04^{b}$ & $0 \cdot 33 \pm 0 \cdot 08^{b}$ & $0 \cdot 33^{*}$ \\
\hline & A & $1 \cdot 48 \pm 0 \cdot 41$ & $1 \cdot 88 \pm 0 \cdot 50$ & $1 \cdot 46 \pm 0 \cdot 37$ & $0 \cdot 99$ \\
\hline \multirow[t]{2}{*}{ Biceps femoris } & NA & $1 \cdot 00 \pm 0 \cdot 31^{\mathrm{a}}$ & $0 \cdot 10 \pm 0 \cdot 02^{b}$ & $0 \cdot 36 \pm 0 \cdot 14^{b}$ & $0 \cdot 36^{*}$ \\
\hline & $\mathrm{A}$ & $1 \cdot 46 \pm 0 \cdot 46^{\mathrm{a}}$ & $0 \cdot 50 \pm 0.08^{b}$ & $1 \cdot 54 \pm 0.35^{a}$ & $1 \cdot 05$ \\
\hline
\end{tabular}

Values are expressed as relative amounts of IGF-II mRNA per total RNA referred to the non-acclimated control vivarium values in each muscle. Data are means \pm S.E.M. Significantly different values $(P<0 \cdot 05)$ in paired comparisons between two groups within either the non-acclimated or acclimated series are denoted by different letters (a vs b), or with asterisks (ratios).

In agreement with these observations, the free 3methylhistidine concentrations in the muscle, a marker of muscle protein breakdown, were not significantly different in the muscle from the non-acclimated spaceflight rats compared with their vivarium controls $(0 \cdot 27 \pm 0 \cdot 17$ vs $0 \cdot 23 \pm 0 \cdot 13 \mu \mathrm{mol} / \mathrm{g}$ tissue in the quadriceps). Anserine, a methylhistidine derivative, was present in the muscle at 10- to 20-fold higher concentrations, but we found no significant difference between the spaceflight and vivarium control rats, even when anserine concentrations were taken into account.

The apoptotic index, assessed by the TUNEL method, was very low in muscles of the control rats and did not exhibit any measurable increase in spaceflight rats (data not shown).

\section{Discussion}

Consistent with published data from previous missions, the rats from the NeuroLab space flight experienced significant loss of muscle mass. Our data demonstrate that this process is associated with an increase in the intramuscular myostatin mRNA concentrations and a decrease in IGF-II mRNA concentrations. The muscle mRNA concentrations of IGF-I, a more widely recognized anabolic growth factor, did not significantly change. The markers of muscle protein breakdown (3-methylhistidine, ubiquitin and proteasome $2 \mathrm{C}$ ), and the apoptotic index, were not significantly increased in the skeletal muscle of the spaceflight rats. We postulate that the ratio between IGF-II and myostatin mRNA levels may serve as an indicator of the homeostatic balance that maintains skeletal muscle mass; a low IGF-II to myostatin mRNA ratio would reflect the alterations in muscle homeostasis that favor the loss of muscle mass in response to microgravity exposure, confinement, or other factors operating during spaceflight.
Because of the cross-sectional nature of the study and the fact that the tissue samples were obtained only at one time point after landing, we do not know whether the changes in myostatin and IGF-II mRNA concentrations were the cause or the result of the spaceflight-related sarcopenia. These changes in gene expression paralleled the decline in muscle weight and were normalized after acclimatization at ground level, suggesting that alterations in the levels of both muscle modulators might play a role in the pathogenesis of muscle wasting occurring during a spaceflight.

The changes in body weight and the weights of most skeletal muscles in the NeuroLab rats were within the range observed in other missions of the same duration (Martin et al. 1988, Baldwin et al. 1990, 1993, Chi et al. 1992); however, the decrease in the tibialis anterior weight during this space flight was somewhat higher than the 7\% change observed in previous flights (Baldwin et al. 1993). A 35\% decrease in fiber size for tibialis anterior has been reported in one mission (Martin et al. 1988).

The pathophysiology of skeletal muscle loss during spaceflight is multifactorial. The loss of gravitational pull during spaceflight is an important contributor to this process, but stress, vibration, exposure to cosmic radiation, confinement, and changes in food intake due to stress and motion sickness may also play a role. The changes in myostatin mRNA and IGF-II expression observed in this experiment could be due to the effects of one or more of these factors that are that are inevitable concomitants of spaceflight, including microgravity.

The ground-based models of microgravity provide greater flexibility and convenience, but do not replicate all the factors associated with spaceflight. In addition, rats use only the base of the simulated cage on the ground, whereas they move along all six surfaces of the cage during space flights. Therefore experimentation in space flights is necessary to examine the effects of this multifactorial process 
even if constrained by the limited number of animals that can be studied and the inability to obtain samples at different time points.

The occurrence of generalized skeletal muscle hypertrophy in cattle and mice with inactivating mutations of the myostatin gene (Kambadur et al. 1997, McPherron et al. 1997, McPherron \& Lee 1997, Grobet et al. 1998, Szabo et al. 1998) suggests that myostatin is a determinant of skeletal muscle mass. The increase in myostatin mRNA and protein expression in the muscles of the spaceflight rats in association with the reduction in muscle mass, and the subsequent normalization of both variables upon reacclimatization to ground conditions, is consistent with the hypothesis that myostatin is an inhibitor of skeletal muscle growth in adult animals. Our data agree with the increase in myostatin mRNA in the gastrocnemius (Carlson et al. 1999) and plantaris (Wehling et al. 2000) muscles of rats during hindlimb suspension and with the normalization of these levels in the plantaris after reloading. The only exception to this consistent inverse correlation of myostatin mRNA levels to muscle mass is the moderate increase in myostatin mRNA we have observed in the gastrocnemius of ground-based control rats after confinement in the flight simulated cages and subsequent acclimatization. In turn, the myostatin-immunoreactive protein levels are higher in the serum and muscle of patients with the AIDS wasting syndrome or agingrelated frailty than in healthy controls (Gonzalez-Cadavid et al. 1998, Yarashesky et al. 1999). Serum myostatinimmunoreactive protein concentrations correlate inversely with fat-free mass in adult humans. Taken together, these data suggest, but do not prove, that upregulation of the myostatin gene might contribute to muscle loss in postnatal life.

We observed only a modest change in IGF-I mRNA concentration in the muscle from the non-acclimated spaceflight rats that did not achieve statistical significance. IGF-I is an important regulator of muscle growth that inhibits apoptosis (Wingertzahn et al. 1998) and promotes cell replication and differentiation, and protein synthesis (Bark et al. 1998). A single previous study reported significant reduction in serum IGF-I levels during microgravity exposure (Strollo et al. 1998). The small sample size may have constrained our ability to detect a modest, but significant decrease in IGF-I mRNA expression.

In contrast to IGF-I, the IGF-II mRNA concentrations in all the muscle groups of the spaceflight rats were markedly lower in comparison with the vivarium controls. IGF-II mRNA concentrations were also decreased in the simulated controls, although this was not accompanied by a parallel reduction in muscle mass. It is possible that the reduction of IGF-II may be related to restriction of locomotion in the simulated cages. IGF-II regulates muscle cell differentiation through myogenic signaling pathways (Marsh et al. 1997, Yoshiko et al. 1998, GayanRamirez et al. 1999, Kaliman et al. 1999, Keller et al.
1999). Recently, a region on the short arm of chromosome 2 containing the locus for the IGF-II gene revealed highly significant lod scores for three of the five phenotypes in pig breeds characterized by increased muscularity and leanness (Jeon et al. 1999, Nezer et al. 1999). IGF-II expression has also been associated with skeletal muscle development in double muscled cattle (Keller et al. 1999) and myofiber regeneration (Marsh et al. 1997, Keller et al. 1999). Our data along with these published observations suggest that IGF-II may be an important regulator of muscle mass in the rat. In vitro studies suggest that these effects may be mediated by the activation of satellite cells (Johnson \& Allen 1995, Petrik et al. 1999) and/or the regulation of apoptosis (Petrik et al. 1999).

The absence of a significant change in the apoptotic index or in proteolytic markers in the muscle of rats exposed to microgravity contrasts with other models of wasting where these processes have been linked to muscle loss (Mitch \& Goldberg 1996, Allen et al. 1997, Wingertzahn et al. 1998). Although apoptosis has been shown to contribute to the remodeling of skeletal muscle in response to hindlimb unweighting (Allen et al. 1997), there are no reports on the apoptotic index in the muscle of animals sent on space flights. Although we did not observe any change in the apoptotic index and proteolysis markers in the NeuroLab rats at the time point we studied, it is plausible that significant changes in muscle protein breakdown and apoptosis might have occurred earlier, preceding the observed change in muscle mass. Our data are consistent with a previous study that showed that 3-methylhistidine excretion (Stein \& Schluter 1997), an indicator of myofibril degradation, is not enhanced after a 2 week space flight. It is possible that skeletal muscle loss during spaceflight might be the result of the inhibition of protein synthesis (Baldwin 1996, Caiozzo et al. 1996, Both \& Criswell 1997, Desplanches 1997). We have shown that recombinant human myostatin protein significantly inhibits protein synthesis in $\mathrm{C} 2 \mathrm{C} 12$ myoblasts and myotubes without affecting protein degradation rates or apoptosis (Taylor et al. 2000)

In summary, the loss of muscle mass during spaceflight is associated with increased myostatin and decreased IGF-II expression; these alterations are normalized upon restoration of normal gravity and caging conditions. The proposal that an alteration in the expression of myostatin and IGF-II may contribute to the multifactorial pathophysiology of sarcopenia, needs to be addressed prospectively in suitable animal models. Our data suggest that the products of the myostatin and IGF-II genes might provide potential targets for the development of counter measures for the prevention of muscle loss during space flights.

\section{Acknowledgements}

The assistance of Kim Webster, Kennedy Space Center, USA, in the provision of the muscle specimens is gratefully 
acknowledged. This study was supported by NIH grants 1RO1DK49296, 1RO1AG14369, Food and Drug Administration Grant/OPD 1397, and RCMI grants P20RR11145-01 (RCMI Clinical Research Initiative) and G12RR03026.

\section{References}

Adam G 1998 Role of insulin-like growth factor-I in the regulation of skeletal muscle adaptation to increased loading. Exercise and Sport Science Reviews 26 31-60.

Allen DL, Linderman JK, Roy RR, Bigbee AJ, Grindeland RE, Mukku V \& Edgerton VR 1997 Apoptosis: a mechanism contributing to remodeling of skeletal muscle in response to hindlimb unweighting. American Journal of Physiology 273 C579-C587.

Amann RP, Deaver DR, Zirkin BR, Grills GS, Sapp WJ, Veeramachaneni DNR, Clemens JW, Banerjee SD, Folmer J, Gruppi CM, Wolgemuth DJ \& Williams CS 1992 Effects of microgravity or simulated launch on testicular function in rats. Journal of Applied Physiology 73 174S-185S.

Baldwin KM 1996 Effect of spaceflight on the functional, biochemical, and metabolic properties of skeletal muscle. Medical Science Sports and Exercise 28 983-987.

Baldwin KM, Herrick RE, Ilyina-Kakueva E \& Oganov VS 1990 Effects of zero gravity on myofibril content and isomyosin distribution in rodent skeletal muscle. FASEB Journal 4 79-83.

Baldwin KM, Herrick RE \& McCue SA 1993 Substrate oxidation capacity in rodent skeletal muscle: effects of exposure to zero gravity. Journal of Applied Physiology 75 2466-2470.

Baldwin KM, White TP, Arnaud SB, Edgerton VR, Kraemer WJ, Kram R, Raab-Cullen D \& Snow CM 1996 Musculoskeletal adaptations to weightlessness and development of effective countermeasures. Medical Science Sports and Exercise 28 1247-1253.

Bamman MM, Clarke MS, Feeback DL, Talmadge RJ, Stevens BR, Lieberman SA \& Greenisen MC 1998 Impact of resistance exercise during bed rest on skeletal muscle sarcopenia and myosin isoform distribution. Journal of Applied Physiology 84 157-163.

Bark TH, McNurlan MA, Lang CH \& Garlick PJ 1998 Increased protein synthesis after acute IGF-I or insulin infusion is localized to muscle in mice. American Journal of Physiology 275 E118-E123.

Booth FW \& Criswell DS 1997 Molecular events underlying skeletal muscle atrophy and the development of effective countermeasures. International Journal of Sports Medicine 18 S265-S269.

Caiozzo VJ, Haddad F, Baker MJ, Herrick RE, Prietto N \& Baldwin KM 1996 Microgravity-induced transformations of myosin isoforms and contractile properties of skeletal muscle. Journal of Applied Physiology 81 123-132.

Carlson CJ, Booth FW \& Gordon SE 1999 Skeletal muscle myostatin mRNA expression is fiber-type specific and increases during hindlimb unloading. American Journal of Physiology 277 R601-R606.

Chi MMY, Choski R, Nemeth P, Krasnov I, Ilyina-Kakueva E, Manchester JK \& Lowry OH 1992 Effects of microgravity and tail suspension on enzymes of individual soleus and tibialis anterior fibers. Journal of Appied Physiology 73 66S-73S.

Desplanches D 1997 Structural and functional adaptations of skeletal muscle to weightlessness. International Journal of Sports Medicine $\mathbf{1 8}$ S259-S264.

Ercolani L, Florence B, Denano M \& Alexander M 1988 Isolation and complete sequence of a functional human glutaraldehyde-3phosphate dehydrogenase gene. Journal of Biological Chemistry 263 15335-15341.

Ferrando AA, Lane HW, Stuart CA, Davis-Street J \& Wolfe RR 1996 Prolonged bed rest decreases skeletal muscle and whole body protein synthesis. American Journal of Physiology 270 E627-E633.
Gayan-Ramirez G, Vanderhoydonc F, Verhoeven G \& Decramer G 1999 Acute treatment with corticosteroids decreases IGF-1 and IGF-2 expression in the rat diaphragm and gastrocnemius. American Journal of Respiratory Critical Care and Medicine 159 283-289.

Gonzalez-Cadavid NF, Taylor WE, Yarasheski K, Sinha-Hikim I, Ma K, Ezzat S, Shen R, Lalani R, Asa S, Mamita M, Nair G, Arver S \& Bhasin S 1998 Organization of the human myostatin gene and expression in healthy men and HIV-infected men with muscle wasting. PNAS 95 14938-14943.

Grobet L, Poncelet D, Royo LJ, Brouwers B, Pirottin D, Michaux C, Menissier F, Zanotti M, Dunner S \& Georges M 1998 Molecular definition of an allelic series of mutations disrupting the myostatin function and causing double-muscling in cattle. Mammalian Genetics 9 210-213.

Highstein SM \& Cohen B 1999 Neurolab mission. Current Opinions in Neurobiology 9 9495-9499.

Husmann I, Soulet L, Gautron J, Martelly I \& Barritault D 1996 Growth factors in skeletal muscle regeneration. Cytokine and Growth Factors Review 7 249-258.

Jeon JT, Carlborg O, Tornsten A, Giuffra E, Amarger V, Chardon P, Andersson-Eklund L, Andersson K, Hansson I, Lundstrom K \& Andersson L 1999 A paternally expressed QTL affecting skeletal and cardiac muscle mass in pigs maps to the IGF2 locus. Nature Genetics 21 157-158.

Johnson SE \& Allen RE 1995 Activation of skeletal muscle satellite cells and the role of fibroblast growth factor receptors. Experimental Cell Research 219 449-453.

Kaliman P, Canicio J, Testar X, Palacin M \& Zorzano A 1999 Insulin-like growth factor-II, phosphatidylinositol 3-kinase, nuclear factor- $\mathrm{\kappa B}$ and inducible nitric-oxide synthase define a common myogenic signaling pathway. Journal of Biological Chemisry 274 17437-17444.

Kambadur R, Sharma M, Smith T \& Bass J 1997 Mutations in myostatin(GDF8) in double-muscled Belgian Blue and Piedmontese cattle. Genome Research 7 910-915.

Keller HL, St Pierre Schneider B, Eppihimer LA \& Cannon JG 1999 Association of IGF-I and IGF-II with myofiber regeneration in vivo. Muscle Nerve 22 347-354.

Kho CJ, Huggins GS, Endege WO, Hsieh CM, Lee ME \& Haber E 1997 Degradation of E2A proteins through a ubiquitinconjugating enzyme, UbcE2A. Journal of Biological Chemistry 272 3845-3851.

Kirkpatrick RB \& Shatzman A 1999 Drosophila S2 system for heterologous gene expression. In Gene Expression Systems, pp 289-330. London: Academic Press.

McPherron AC \& Lee SJ 1997 Double muscling in cattle due to mutations in the myostatin gene. PNAS 94 12457-12461.

McPherron AC, Lawler AM \& Lee SJ 1997 Regulation of skeletal muscle mass in mice by a new TGF- $\beta$ superfamily member. Nature $38783-90$.

Mallidis C, Bhasin S, Matsumoto A, Shen R \& Gonzalez-Cadavid NF 1999 Skeletal muscle myostatin in a rat model of aging-related sarcopenia. The Endocrine Society 81st Annual Meeting Proceedings $\mathbf{7 3}$ (OR9-1).

Marsh DR, Criswell DS, Hamilton MT \& Booth FW 1997 Association of insulin-like growth factor mRNA expressions with muscle regeneration in young, adult, and old rats. American Journal of Physiology 273 R353-R358.

Martin TP, Edgerton VR \& Grindeland RE 1988 Influence of spaceflight on rat skeletal muscle. Journal of Applied Physiology $\mathbf{6 5}$ 2318-2325.

Merrill AH Jr, Wang E, Mullins RE, Grindeland RE \& Popova IA 1992 Analysis of plasma for metabolic and hormonal changes in rats flown aboard COSMOS 2044. Journal of Applied Physiology 73 132S-135S.

Mitch WE \& Goldberg AL 1996 Mechanisms of muscle wasting. The role of the ubiquitin-proteasome pathway. New England Journal of Medicine 335 1897-1905. 
Mozdziak PE, Truong Q, Macius A \& Schultz E 1998 Hindlimb suspension reduces muscle regeneration. European Journal of Applied Physiology 78 36-14.

Nezer C, Moreau L, Brouwers B, Coppieters W, Detilleux J, Hanset R, Karim L, Kvasz A, Leroy P \& Georges M 1999 An imprinted QTL with major effect on muscle mass and fat deposition maps to the IGF2 locus in pigs. Nature Genetics 21 155-156.

Petrik J, Pell JM, Arany E, McDonald TJ, Dean WL, Reik W \& Hill DJ 1999 Over expression of insulin-like growth factor-II in transgenic mice is associated with pancreatic islet cell hyperplasia. Endocrinology 140 2353-2363.

Pfaffl M, Meyer HH \& Sauerwein H 1998 Quantification of insulinlike growth factor-I (IGF-1) mRNA: development and validation of an internally standardised competitive reverse transcriptionpolymerase chain reaction. Experimental and Clinical Endocrinology and Diabetes 106 506-513.

Sinha-Hikim AP \& Swerdloff RS 1995 Temporal and stage-specific effects of recombinant human follicle-stimulating hormone on the maintenance of spermatogenesis in gonadotropin-releasing hormone antagonist-treated rat. Endocrinology 136 253-261.

Stein TP \& Schluter MD 1997 Human skeletal muscle protein breakdown during spaceflight. American Journal of Physiology 272 E688-E22695.

Strollo F, Norsk P, Roecker L, Strollo G, More M, Bollanti L, Riondino G \& Scano A 1998a Indirect evidence of CNS adrenergic pathways activation during spaceflight. Aviation, Space and Environmental Medicine 69 777-780.

Strollo F, Riondino G, Harris B, Strollo G, Casarosa E, Mangrossa N, Ferretti C \& Luisi M 1998 b The effect of microgravity on testicular androgen secretion. Aviation, Space and Environmental Medicine 69 133-136.

Suliman IA, Lindgren JU, Gillberg PG, Elhassan AM, Monneron C \& Adem A 1999 Alteration of spinal cord IGF-I receptors and skeletal muscle IGF-I after hind-limb immobilization in the rat. Neuroreport $101195-1196$.

Szabo G, Dallman G, Muller G, Patthy L, Soller M \& Varga L 1998 A deletion in the myostatin gene causes the compact (Cmpt) hypermuscular mutation in mice. Mammalian Genetics 9 671-672.

Tarnuzzer RW, Macauley SP, Farmerie WG, Caballero S, Ghassemifar MR, Anderson JT, Robinson CP, Grant MB,
Humphreys-Beher MG, Franzen LL, Peck AB \& Schultz GS 1996 Competitive RNA templates for detection and quantitation of growth factors, cytokines, extracellular matrix components and matrix metalloproteinases by RT-PCR. Biotechniques 20 670-674.

Tayek JA 1996 Effects of tumor necrosis factor $\alpha$ on skeletal muscle amino acid metabolism studied in vivo. Journal of the American College of Nutrition 15 164-168.

Taylor W, Bhasin S, Artaza J, Byhower F, Shen R, Assam M, Kull FC \& Gonzalez-Cadavid NF 2000 Myostatin inhibits cell proliferation and protein synthesis in skeletal muscle cells. American Journal of Physiology (In press).

Vandenburgh H, Chromiak J, Shansky J, Del Tatto M \& Lemaire J 1999 Space travel directly induces skeletal muscle atrophy. FASEB Journal 13 1031-1038.

Vernikos J 1996 Human physiology in space. Bioassays 18 1029-1037.

Wehling M, Cai R \& Tidball JG 2000 Modulation of myostatin expression during modified muscle use. FASEB Journal 14 103-110.

Welle S \& Thornton C 1997 Insulin-like growth factor-I, actin, and myosin heavy chain messenger RNAs in skeletal muscle after an injection of growth hormone in subjects over 60 years old. Journal of Endocrinology 155 93-97.

Wingertzahn MA, Zdanowicz MM \& Slonim AE. 1998 Insulin-like growth factor-I and high protein diet decrease calpain-mediated proteolysis in murine muscular dystrophy. Proceedings of the Society of Experimental Biology and Medicine 218 244-250.

Yarashesky KE, Bhasin S Sinha-Hikim I, Pak-Loduca J \& GonzalezCadavid NF 1999 Serum myostatin-immunoreactive protein concentration is increased with muscle wasting and advanced age. The Endocrine Society 81st Annual Meeting Proceedings $\mathbf{7 4}$ (OR9-2).

Yoshiko Y, Hirao K \& Maeda N 1998 Dexamethasone regulates the actions of endogenous insulin-like growth factor-II during myogenic differentiation. Life Sciences 63 77-85.

Received 11 April 2000

Revised manuscript received 1 August 2000

Accepted 15 August 2000 